\title{
CONSTRUÇÃO SUSTENTÁVEL E MEIO AMBIENTE DO TRABALHO
}

\author{
SUSTAINABLE BUILDING AND ENVIRONMENTAL WORK
}

\author{
Veronica Altef Barros ${ }^{1}$ \\ Norma Sueli Padilha ${ }^{2}$
}

\section{RESUMO}

O trabalho tem como tema o meio ambiente de trabalho na construção sustentável, uma vez que a mitigação dos impactos ambientais com novos processos de produção não significa a redução dos riscos no ambiente de trabalho. Assim, tem o propósito de analisar as práticas dos atores sociais quanto às condições de trabalho no contexto da sustentabilidade. Constatou-se que é necessária uma abordagem rigorosa quanto aos riscos tradicionais em relação à segurança e à saúde dos trabalhadores, bem como, da identificação dos riscos novos. Utilizouse como método de abordagem a pesquisa qualitativa e como procedimentos, a pesquisa bibliográfica e documental.

Palavras-Chave: Construção sustentável; Meio Ambiente do trabalho; Trabalho decente; Condições de Trabalho; Sustentabilidade social e ambiental.

\begin{abstract}
The subject is about the working environment in sustainable building, since the mitigation of environmental impacts with new production processes does not mean the reduction of risks in the workplace. So, it has the purpose of analyzing the practices of social actors about the working conditions in the context of sustainability. It was found that a rigorous approach is needed as the traditional risks related to the safety and health of workers as well as the

\footnotetext{
${ }^{1}$ Pós-doutoranda/Direito Ambiental Internacional pela Universidade Católica de Santos - UNIFESP, São Paulo, (Brasil). Professora/ cursos de graduação e pós-graduação. (Universidade Católica de Santos).

E-mail: normasp@uol.com.br

${ }^{2}$ Supervisora do Estágio Pós-doutoral/ Direito Ambiental Internacional pela Universidade Católica de Santos UNIFESP, São Paulo, (Brasil). Professora do Programa de Mestrado e Doutorado/Direito da Universidade Católica de Santos. Professora Associada da UFMS. E-mail: veronicaaltef@unisantos.br
} 
identification of new risks. The method used is qualitative research, and on the procedures, documentary and bibliographic research.

Keywords: Sustainable building; Environmental work; Decent work; Working conditions; Social and environmental sustainability.

\section{INTRODUÇÃO}

O setor da indústria da construção considera-se sustentável quando a concepção e o conjunto das atividades relacionadas em seu ciclo de vida minimizem os impactos ambientais, e, maximizem benefícios sociais e sua viabilidade econômica. Contudo, tanto as certificações internacionais e os documentos nacionais abordados concentram-se no aspecto ambiental.

Isso nos leva a questionar a concepção de sustentabilidade do setor, em razão dos riscos e condições precárias de trabalho existentes na indústria da construção, pois não se pode conceber sustentabilidade e, por consequência, trabalho decente sem que sejam observados, além dos impactos ambientais, os aspectos ligados ao trabalho.

Nessa linha de raciocínio, o presente trabalho tem como objetivo analisar a concepção de sustentabilidade do setor a partir de documentos e práticas elaboradas pelos atores sociais correspondentes, tendo como enfoque aquelas que dizem respeito aos trabalhadores.

A fim de alcançar os resultados almejados, utiliza-se como método de abordagem a pesquisa qualitativa, visto que os dados já foram quantificados em estudos anteriores. Quanto aos procedimentos, serão utilizadas as pesquisas documental e bibliográfica, em razão do levantamento e análise dos relatórios e estudos já desenvolvidos.

1. Trabalho decente e desenvolvimento sustentável:

Em 2002, a Conferência Mundial de Desenvolvimento Sustentável, realizada em Johannesburgo, adotou o compromisso de promover a integração dos três componentes do desenvolvimento sustentável - desenvolvimento econômico, social e proteção do meio ambiente - como pilares que se reforçam mutuamente (ONU, 2002), o qual se baseou no Princípio 4 da Declaração do Rio sobre o Meio Ambiente e o Desenvolvimento: “A fim de alcançar o desenvolvimento sustentável, a proteção do meio ambiente deve constituir-se parte 
integrante do processo de desenvolvimento e não poderá ser considerada de forma isolada." (ONU, 1992b).

A Conferência das Nações Unidas sobre o desenvolvimento sustentável, realizada no Rio de Janeiro (Rio +20), em 2012, por sua vez, debateu a temática da economia verde no contexto da redução da pobreza, do desenvolvimento sustentável e da governança do ambiente como instrumento de equilíbrio das três dimensões do desenvolvimento sustentável, ambiental, econômica e social.

O Programa das Nações Unidas para o Meio Ambiente (PNUMA) define a economia verde como aquela que resulta no aprimoramento do bem-estar humano e social, ao mesmo tempo em que reduz, significativamente, os riscos ambientais e a escassez de recursos ecológicos. Ou seja, uma economia de baixo carbono, com utilização eficiente dos recursos naturais e com inclusão social. (PNUMA, 2012, p.4)

Nesse sentido, a proteção do meio ambiente estabelece uma necessária transição para uma economia sustentável, a qual provoca repercussões nas estruturas de produção e consumo, e, por consequência, nas empresas e no mundo do trabalho.

Os novos processos de produção e utilização de novas tecnologias, além de proporcionarem mudanças nos postos de trabalho, resultarão também em novos riscos para os trabalhadores como, por exemplo, na instalação de painéis solares, em que os riscos elétricos se combinam com o risco de trabalhar em altura. (OIT, 2012, p.4-5)

Diante desse cenário, a segurança e a saúde do trabalhador são consideradas fatores importantes no debate sobre a economia verde. É necessário criar uma consciência sobre os efeitos dos riscos novos e emergentes associados às tecnologias verdes que alteram os modos de produção, garantindo, desde o princípio, que o trabalho decorrente dessa mudança seja seguro, e ao mesmo tempo, reduzam ao mínimo os efeitos negativos no meio ambiente. (OIT, 2012, p.3)

\subsection{Trabalho decente:}

Em setembro de 2000, foi aprovada a Declaração do Milênio, em que os países membros das Nações Unidas se comprometeram a reduzir os níveis de extrema pobreza e estabeleceram oito objetivos, conhecidos como Objetivos de Desenvolvimento do Milênio, com prazo fixado para 2015.

O objetivo 1 dispõe sobre a erradicação da pobreza extrema e da fome. Para concretizar este objetivo foram estabelecidas metas, entre elas, a meta 1.B que preconiza a 
necessidade de "alcançar o emprego pleno e produtivo e um trabalho decente para todos, inclusive para as mulheres e jovens". (grifo nosso)

O Relatório da Conferência Rio +20 (2012) aponta que a erradicação da pobreza, o emprego pleno e produtivo, o trabalho decente para todos, assim como a integração e a proteção sociais estão relacionadas entre si e se reforçam mutuamente, e que se devem criar mecanismos propícios para promovê-los em todos os níveis, bem como, ressaltou a preocupação com as condições do mercado de trabalho e grande escassez de oportunidades de trabalho decente. (ONU, 2012, p. 32)

A nova Agenda para o Desenvolvimento sustentável (Agenda 2030) apresenta dezessete objetivos. O objetivo n.8 dispõe: "promover crescimento econômico, inclusivo e sustentável, o emprego pleno e produtivo e o trabalho decente para todos". E entre as metas propostas (8.5), alcançar, para 2030, “o emprego pleno e produtivo e o trabalho decente para todos os homens e mulheres, inclusive os jovens e as pessoas com deficiência, e a igualdade de remuneração pelo trabalho de igual valor.” (ONU, 2015, grifo nosso).

Assim, o trabalho decente para todos é considerado elemento fundamental, juntamente com outros fatores, para o desenvolvimento sustentável e a erradicação da pobreza, na medida em que o acesso ao emprego, a garantia dos direitos trabalhistas, o diálogo social e a proteção social contribuem para a promoção da justiça social e distributiva, e, de condições de vida digna.

\subsubsection{Trabalho decente e meio ambiente do trabalho:}

O conceito de trabalho decente engloba como elementos característicos aqueles que abrangem os quatro objetivos estratégicos da OIT: a promoção dos direitos fundamentais do trabalho, o emprego a proteção social e o diálogo social, a fim de alcançar liberdade, equidade, seguridade e dignidade humana.

$\mathrm{O}$ art. $7^{\circ}$ do Pacto Internacional sobre os Direitos Econômicos, Sociais e Culturais estabelece que: "Os Estados Partes no presente Pacto reconhecem o direito de todas as pessoas de gozar de condições de trabalho justas e favoráveis, que assegurem em especial: [...] b) Condições de trabalho seguras e higiênicas".

Portanto, o direito ao meio ambiente do trabalho seguro é reconhecido como um direito humano fundamental, por consequência, sua promoção é essencial para a consecução do trabalho decente. 
Desse modo, para que haja trabalho decente frente às mudanças no modo de produção na esteira da sustentabilidade, serão necessárias revisões das normas de proteção, uma vez que novos riscos no ambiente de trabalho poderão surgir. O "esverdeamento" de um setor não implica, automaticamente, em trabalho decente. Os impactos ambientais poderão ser mitigados, porém, os processos e tecnologias empregadas poderão afetar as condições de trabalho.

2. Meio ambiente do trabalho e as normas de proteção:

Norma Sueli Padilha (2002, p.35), na avaliação dos aspectos históricos que influenciaram o meio ambiente do trabalho, sintetiza:

\begin{abstract}
O desenvolvimento do capitalismo, através da história, dadas as exigências que o levaram a reorganizar-se com vistas à globalização da economia, bem como a incorporação da ciência e da tecnologia ao processo produtivo, a adoção de novas bases materiais de produção, de novas formas de gestão e organização do trabalho têm representado mudanças radicais nos meios de produção, com reflexos inúmeros em toda a extensão da atividade econômica e na vida da classe trabalhadora.
\end{abstract}

Segundo Júlio César de Sá da Rocha (2002, p. 127 e 131), “o meio ambiente do trabalho representa todos os elementos, inter-relações e condições que influenciam o trabalhador em sua saúde física e mental, comportamento e valores reunidos no locus do trabalho." Acrescenta o autor que "o ambiente do trabalho constitui-se esfera circundante do trabalho, espaço transformado pela ação antrópica."

Nesse sentido, o ambiente do trabalho apresenta diversos riscos e agressões que afetam a saúde e a integridade física e mental do trabalhador em maior ou menor grau, dependendo do setor e ocupação, os quais foram se modificando à medida que se transformavam os modos de produção e a organização do trabalho, e, por consequência, provocaram a elaboração e as atualizações das normas de proteção.

\title{
2.1 Normas de Proteção no âmbito da OIT e no Brasil:
}

O tratado de Versailles (1919), ao criar a OIT, incluiu na sua competência a proteção contra os acidentes do trabalho e as doenças profissionais, cujos riscos devem ser eliminados, neutralizados ou reduzidos por medidas apropriadas da engenharia de segurança e da medicina do trabalho. (SUSSEKIND, 1999, p. 928)

Duas convenções internacionais do trabalho podem ser destacadas a Convenção n. 155 (1981), ratificada pelo Brasil em 1992, que estabelece diretrizes gerais de segurança e 
saúde no trabalho; e a Convenção n. 161 (1985), ratificada pelo Brasil em 1990, que trata dos serviços de saúde.

A Constituição Federal de 1988 inclui entre os direitos sociais do trabalhador a redução dos riscos inerentes ao trabalho (XXII); adicional de remuneração para as atividades penosas, insalubres ou perigosas, na forma da lei (XXIII); seguro contra acidentes de trabalho, a cargo do empregador, sem excluir a indenização a que este está obrigado, quando incorrer em dolo ou culpa; (XXVIII).

$\mathrm{O}$ art. 170 da $\mathrm{CF} / 88$ estabelece a ordem econômica tem como objetivo assegurar a todos existência digna, com fundamento na valorização do trabalho humano e a livre iniciativa, observados alguns princípios, entre eles a defesa do meio ambiente. Assim, qualquer exercício de atividade econômica deve respeitar o meio ambiente, inclusive o meio ambiente do trabalho, tendo em vista que a segurança e proteção da saúde do trabalho são direitos fundamentais do trabalho e essencial para que haja a efetiva valorização do trabalho.

A Consolidação das Leis do Trabalho (CLT), por sua vez, possui capítulo específico de Segurança e Medicina do Trabalho (Capítulo V), em que enumera normas não exaustivas, pois atribui ao próprio Ministério do Trabalho: "estabelecer disposições complementares às normas de que trata este Capítulo, tendo em vista as peculiaridades de cada atividade ou setor de trabalho" (art.200, CLT), as quais são denominadas normas regulamentadoras (NR).

As normas regulamentadoras, aprovadas pela Portaria n. 3214/78, estabelecem os padrões a serem seguidos pelos empregadores, a fim de adequação do ambiente de trabalho e prevenção da integridade do trabalhador.

A NR 1 diz respeito às Disposições Gerais. No itens 1.1, define que as "Normas Regulamentadoras - NR, relativas à segurança e medicina do trabalho, são de observância obrigatória pelas empresas privadas e públicas e pelos órgãos públicos da administração direta e indireta, bem como pelos órgãos dos Poderes Legislativo e Judiciário, que possuam empregados regidos pela Consolidação das Leis do Trabalho - CLT."

Vale destacar que aquelas não desobrigam "as empresas do cumprimento de outras disposições que, com relação à matéria, sejam incluídas em códigos de obras ou regulamentos sanitários dos Estados ou Municípios, e outras, oriundas de convenções e acordos coletivos de trabalho." (NR 1, item 1.2)

Como mencionado no subtítulo anterior, o exercício de qualquer atividade profissional provoca riscos. No entanto, em alguns setores, os riscos são mais elevados 
ocasionando um histórico maior de número de acidentes do trabalho como na construção civil e trabalho em minas. (SUSSEKIND, 1999, p. 920)

No que diz respeito ao setor da Construção, a OIT possui a Convenção n.167 (1988), ratificada pelo Brasil em 2006, e a Recomendação n. 172 (1988). No Brasil, medidas de controle e sistemas preventivos de segurança nos processos, nas condições e no meio ambiente de trabalho na Indústria da Construção são tratadas na NR-18, que teve várias atualizações posteriores.

O item 18.1.2 delimita como atividades da Indústria da Construção as constantes do Quadro I, Código da Atividade Específica, da NR 4 - Serviços Especializados em Engenharia de Segurança e em Medicina do Trabalho e as atividades e serviços de demolição, reparo, pintura, limpeza e manutenção de edifícios em geral, de qualquer número de pavimentos ou tipo de construção, inclusive manutenção de obras de urbanização e paisagismo.

3. A indústria da construção no Brasil e as condições de trabalho:

A cadeia produtiva da indústria da construção é bastante ampla e diversificada, assim, para efeito do presente trabalho, utiliza-se como definição de indústria da construção aquela disposta pela “Agenda 21 para a Construção Sustentável em países em desenvolvimento", bem como, na NR 4, além daquelas definidas no item 18.1.2 da NR 18 e descritas no item anterior.

O primeiro documento define a construção como um amplo processo para a realização de assentamentos humanos e de criação de infraestrutura com vistas ao desenvolvimento. Nesse sentido, inclui a extração e beneficiamento de matérias-primas; a fabricação de materiais e de componentes de construção; o ciclo do projeto de construção, de viabilidade para desconstrução, e a gestão e operação do ambiente construído. (UNEP; CIB, 2002, p. 14)

A NR 4 especifica as atividades da indústria da construção em três categorias: construção de edificações; obras de infra-estrutura e serviços especializados em construção, quais sejam:

Construção de edifícios: 41.1 Incorporação de empreendimentos imobiliários; 41.107 Incorporação de empreendimentos imobiliários; 41.2 Construção de edifícios; 41.20-4 Construção de edifícios;

Obras de infraestrutura: 42.1 Construção de rodovias, ferrovias, obras urbanas e obras-de-arte especiais; 42.11-1 Construção de rodovias e ferrovias; 42.12-0 Construção de 
obras-de-arte especiais; 42.13-8 Obras de urbanização - ruas, praças e calçadas; 42.2 Obras de infraestrutura para energia elétrica, telecomunicações, água, esgoto e transporte por dutos; 42.21-9 Obras para geração e distribuição de energia elétrica e para telecomunicações; 42.227 Construção de redes de abastecimento de água, coleta de esgoto e construções correlatas; 42.23-5 Construção de redes de transportes por dutos, exceto para água e esgoto; 42.9 Construção de outras obras de infra-estrutura; 42.91-0 Obras portuárias, marítimas e fluviais; 42.92-8 Montagem de instalações industriais e de estruturas metálicas; 42.99-5 Obras de engenharia civil não especificadas anteriormente.

Serviços especializados para construção: 43.1 Demolição e preparação do terreno; 43.11-8 Demolição e preparação de canteiros de obras; 43.12-6 Perfurações e sondagens; 43.13-4 Obras de terraplenagem; 43.19-3 Serviços de preparação do terreno não especificados anteriormente; 43.2 Instalações elétricas, hidráulicas e outras instalações em construções; 43.21-5 Instalações elétricas; 43.22-3 Instalações hidráulicas, de sistemas de ventilação e refrigeração; 43.29-1 Obras de instalações em construções não especificadas anteriormente;

43.3 Obras de acabamento; 43.30-4 Obras de acabamento; 43.9 Outros serviços especializados para construção; 43.91-6 Obras de fundações; 43.99-1 Serviços especializados para construção não especificados anteriormente.

Em razão dessa heterogeneidade das atividades econômicas envolvidas tanto em termos de tamanho das empresas quanto ao nível tecnológico, inclusive, ainda depende muito de trabalhos manuais e de atividades desgastantes e perigosas, dois fatores são preponderantes na ocorrência de acidente de trabalho na indústria da construção: a intensidade do processo de produção e a falta de qualificação profissional. (GONÇALVES, 2008, passim)

Como mencionado, a NR 18, sofreu várias alterações, a última ocorreu em dezembro de 2015 pela Portaria n. 208 do Ministério do Trabalho e Previdência Social. Antes da recente mudança, Marcelo Fabiano Costella e outros autores realizaram um estudo com o objetivo de verificar a adequação das condições de segurança do trabalho nos canteiros de obra de diferentes portes, para tanto, foi elaborada "uma lista de verificação em que se apresenta o aperfeiçoamento de alguns aspectos da norma expostos de maneira autoexplicativa, sem a necessidade de grande experiência ou conhecimento aprofundado na NR-18 para sua utilização". (COSTELLA; JUNGES; PILZ, 2014, p. 88)

Com vistas ao enfoque do presente trabalho, dar-se-á enfoque nos resultados levantados em relação às condições de trabalho, mesmo que a referida pesquisa tenha sido 
feita antes da atualização, quais sejam: 1. "Os principais envolvidos nas obras (engenheiro, mestre de obra, encarregado, etc.) não possuem conhecimento detalhado das exigências da NR-18"; 2. "Existem diversos canteiros de obra em que as condições de trabalho ofertadas não são exemplares"; 3. "Os resultados da avaliação do cumprimento da NR-18 em função do porte de cada obra residencial, inédita, permitiram observar as melhores condições de trabalho dos canteiros de grande porte, ficando estes com média geral de 6,47, enquanto as obras médias obtiveram nota 4,56 , e as de pequeno porte, somente $1,97 \%$. Diante da análise dos dados, concluiu-se que "o descaso com a segurança do trabalho nos canteiros de pequeno porte, [...] as pequenas empresas não possuíam habilidades gerenciais de SST e, consequentemente, havia baixa valorização dos trabalhadores". (COSTELLA; JUNGES; PILZ, 2014, p. 99-100)

Esse cenário de precarização das condições de trabalho, falta de capacitação e qualificação profissionais e índices elevados de acidentes de trabalho ocorre em razão do setor absorver um grande número de trabalhadores, com baixa escolaridade, em diferentes formas de organização do trabalho, desde autônomos a terceirização de atividade e subcontratações, com alta rotatividade da mão de obra, e, em muitos casos, trabalhos informais. (BRASIL, 2014, p.4)

Nota-se que todos esses aspectos afrontam o paradigma de trabalho decente que, como demonstrado, é elemento fundamental no contexto do desenvolvimento sustentável, além do preconizado no art. $170 \mathrm{CF} / 88$, quando estabelece que o exercício da atividade econômica deva observar, entre outros princípios, a defesa do meio ambiente, mas, com base na valorização do trabalho humano.

Assim, a concepção de sustentabilidade em qualquer atividade econômica deve contemplar a promoção do emprego e do meio ambiente do trabalho adequados. Nesse sentido, uma proposta para construção sustentável deve implementar ações que alterem a realidade exposta, a qual é inaceitável por si só. Passe-se a análise da concepção de sustentabilidade no setor.

\subsection{Construção sustentável:}

Frente a sua abrangência, a indústria da construção tem sido considerada um dos setores que mais gera impactos ambientais, em razão do alto consumo de recursos naturais e de energia, além da geração de resíduos sólidos, líquidos e gasosos. 
Tais impactos estão presentes em todas as atividades que integram o setor, a título de exemplificação, pode-se citar tanto a extração de recursos naturais e seu processamento, que requer energia e implica em emissões de gases de efeito estufa (GEE) como o transporte dos materiais e dos resíduos de construção, manutenção e demolição; as perdas dos materiais no transporte, na comercialização e na fase de execução; inclusive, nas elaborações de projetos que apresentam deficiências nas escolhas dos materiais, provocando reposições precoces e renovação do ciclo de impactos ambientais. (CBCS, 2014, p. 73)

Segundo o Programa das Nações Unidas para o Meio Ambiente (PNUMA), a indústria da construção civil é responsável "por $40 \%$ do consumo energético global, 30\% das emissões de GEE relacionadas com a energia, aproximadamente $12 \%$ do consumo de água, cerca de $40 \%$ dos resíduos, e emprega $10 \%$ da força de trabalho, incluindo muitas $\mathrm{PME}^{3}$ ". (UNEP, [20--])

Na Conferência das Nações Unidas sobre o Meio Ambiente e Desenvolvimento, realizada em junho de 1992 no Rio de Janeiro, foi adotada a Agenda 21 Global, um programa desenvolvido em 40 capítulos, em que foram identificados os problemas prioritários e apresentadas as ações, tendo em vista a construção de um novo padrão de desenvolvimento. (desenvolvimento sustentável). (ONU, 1992)

Entre os temas, estão as atividades da construção em razão dos seguintes fatores: 1) fatores econômicos e sociais: aquelas foram consideradas "vitais para a concretização das metas nacionais de desenvolvimento socioeconômico: proporcionar habitação, infraestrutura e emprego"; 2) fatores de proteção ao meio ambiente: "por meio do esgotamento da base de recursos naturais, da degradação de zonas ecológicas frágeis, da contaminação química e do uso de materiais de construção nocivos para a saúde humana, elas podem ser uma fonte importante de danos ambientais". (ONU, 1992)

Diante do cenário da indústria da construção em relação ao meio ambiente e as mudanças preconizadas pela Agenda 21 Global, houve o consenso da necessidade de uma Agenda Internacional sobre Construção Sustentável, desse modo, em 1999, o Conselho Internacional para a Investigação e Inovação na Construção (CIB) publicou a Agenda 21 sobre Construção Sustentável.(CIB, 1999)

Após esse documento, foi elaborado um específico para os países em desenvolvimento, a fim de melhor compreender os desafios do setor da construção e formular

\footnotetext{
${ }^{3}$ Pequenas e Médias Empresas - PME
} 
ações que contribuíssem para a concretização dos princípios da sustentabilidade naqueles países. Foi denominada de Agenda 21 para a Construção Sustentável em países em desenvolvimento. (UNEP; CIB, 2002, passim)

Nos termos do referido documento, considera-se construção sustentável como:

\begin{abstract}
Implica em um pensamento holístico no que diz respeito à construção e gestão do ambiente construído, tendo uma perspectiva de ciclo de vida. Isso implica não só novos projetos de construção ambientalmente orientados, mas também novos procedimentos de operação e manutenção ecológicos. Não só os materiais de construção e componentes devem ser produzidos de forma sustentável , mas seu uso deve também responder às novas exigências decorrentes dos pré-requisitos ambientais holísticos. (UNEP; CIB, 2002, p. 9)
\end{abstract}

\title{
Por pensamento holístico em relação à construção sustentável tem-se que
}

os princípios do desenvolvimento sustentável são aplicados à construção global desde o ciclo da extração e beneficiamento de matérias-primas, através do planejamento, concepção e construção de edifícios e infra-estrutura, até a sua definitiva desconstrução e gestão do resíduos resultantes. É um processo global com o objetivo de restaurar e manter a harmonia entre o natural e o ambiente construído, ao mesmo tempo que cria assentamentos que afirmam a dignidade humana $\mathrm{e}$ encorajam equidade econômica. (UNEP; CIB, 2002, p. 6)

No Brasil, o Ministério do Meio Ambiente, na esteira da sustentabilidade proposta nas Agendas referidas, recomenda:

- $\quad$ mudança dos conceitos da arquitetura convencional na direção de projetos flexíveis com possibilidade de readequação para futuras mudanças de uso e atendimento de novas necessidades, reduzindo as demolições;

- $\quad$ busca de soluções que potencializem o uso racional de energia ou de energias renováveis;

- $\quad$ gestão ecológica da água;

- $\quad$ redução do uso de materiais com alto impacto ambiental;

- redução dos resíduos da construção com modulação de componentes para diminuir perdas e especificações que permitam a reutilização de materiais. (BRASIL, [s.d])

Para tanto, o Ministério do Meio Ambiente elaborou um conjunto de prescrições, abrangendo aspectos urbanísticos e edilícios de forma a contribuir para iniciativas de construção sustentável, e, adequadas à realidade brasileira. (BRASIL, [s.d.])

Implantação urbana: "adaptação à topografia local, com redução da movimentação de terra; preservação de espécies nativas; previsão de ruas e caminhos que privilegiem o pedestre e o ciclista e contemplem a acessibilidade universal; previsão de espaços de uso comum para integração da comunidade; e, preferencialmente, de usos do solo diversificados, minimizando os deslocamentos". 
Edificação: "adequação do projeto ao clima do local, minimizando o consumo de energia e otimizando as condições de ventilação, iluminação e aquecimento naturais; previsão de requisitos de acessibilidade para pessoas com mobilidade reduzida ou, no mínimo, possibilidade de adaptação posterior; atenção para a orientação solar adequada, evitando-se a repetição do mesmo projeto em orientações diferentes; utilização de coberturas verdes; e a suspensão da construção do solo (a depender do clima)."

Escolha dos materiais de construção: "a utilização de materiais disponíveis no local, pouco processados, não tóxicos, potencialmente recicláveis, culturalmente aceitos, propícios para a autoconstrução e para a construção em regime de mutirões, com conteúdo reciclado. Além disso, deve-se evitar sempre o uso de materiais químicos prejudiciais à saúde humana ou ao meio ambiente, como amianto, CFC, HCFC, formaldeído, policloreto de vinila (PVC), tratamento de madeira com CCA, entre outros."

Resíduos da construção civil: “deve-se atentar para a sua redução e disposição adequada, promovendo-se a reciclagem e reuso dos materiais."

Energia: "recomenda-se o uso do coletor solar térmico para aquecimento de água, de energia eólica para bombeamento de água e de energia solar fotovoltaica, com possibilidade de se injetar o excedente na rede pública."

Água e esgoto: "prever a coleta e utilização de águas pluviais; utilização de dispositivos economizadores de água, reuso de águas, tratamento adequado de esgoto no local e, quando possível, o uso de banheiro seco."

Tratamento das áreas externas: "recomenda-se a valorização dos elementos naturais no tratamento paisagístico e o uso de espécies nativas, a destinação de espaços para produção de alimentos e compostagem de resíduos orgânicos, o uso de reciclados da construção na pavimentação e de pavimentação permeável, a previsão de passeios sombreados no verão e ensolarados no inverno."

Estudo realizado por Leila Florim e Osvaldo Quelhas (2004, p. 129-130) sobre construção sustentável alerta que para um empreendimento ser considerado comprometido com a sustentabilidade nos seus aspectos econômicos, sociais e ambientais, deve-se levar em conta "a definição da demanda, na fase de planejamento, até a manutenção na fase de uso e ocupação", uma vez que medidas corretivas são financeira e socialmente onerosas devido à "vultuosidade dos recursos necessários para reverter este quadro, com obras frequentemente 
insatisfatórias em nível de desempenho. É necessária a adoção integrada de medidas preventivas".

No entanto, ainda não há, no Brasil, regulamentação que imponha tais medidas. Existem certificações, com métodos próprios, criadas em outros países, e, que passaram a ser utilizadas em território nacional de maneira voluntária como mecanismo de diferencial competitivo (CNI, CBIC, 2012, p, 36), bem como, a classificação de sustentabilidade elaborada pela Caixa Econômica Federal nos financiamentos de projetos de construção habitacional, o Selo Casa Azul Caixa.

Entre os referidos métodos podem ser citados: o método inglês Building Research Establishment Environmental Assessment (BREEAM); o método americano Leadership in Energy and Environmental Design (LEED) e o método francês HQE® - Haute Qualité Environmentale (HQE). Porém, tais métodos estrangeiros se concentram na qualidade ambiental quase não fazem referência aos aspectos sociais e econômicos, diferentemente do Selo Casa Azul Caixa. (SALGADO; CHATELET; FERNANDEZ, 2012, p. $82-3$ e 97)

Como o presente trabalho desenvolve-se a partir da concepção de sustentabilidade nas três dimensões (ambiental, social e econômica), para análise das propostas de sustentabilidade no setor da construção no Brasil, foram selecionados documentos dirigidos ao setor que estivessem alinhados com tal concepção: o guia Selo Casa Azul Caixa, e, o Programa Construção Sustentável da Câmara Brasileira da Construção Civil (CBIC).

O Selo Casa Azul Caixa é o primeiro sistema de classificação da sustentabilidade de projetos, desenvolvido no Brasil, para a construção habitacional, que "busca reconhecer os empreendimentos que adotam soluções mais eficientes aplicadas à construção, ao uso, à ocupação e à manutenção das edificações, objetivando incentivar o uso racional de recursos naturais e a melhoria da qualidade da habitação e de seu entorno”. (JOHN; PRADO, 2010, p. 21)

Esse instrumento de classificação possui 53 critérios de avaliação, distribuídos em seis categorias. Serão apresentadas as categorias e os critérios em linhas gerais.

Categoria 1, Qualidade urbana: qualidade do entorno e melhorias; recuperação de áreas degradadas; reabilitação de imóveis. Categoria 2, Projeto e conforto: paisagismo; flexibilidade de projeto; relação com a vizinhança; local para coleta seletiva; desempenho térmico (vedações; orientação ao sol e ventos); iluminação natural de áreas comuns; adequação às condições físicas do terreno; e outros. Categoria 3, Eficiência energética: lâmpadas de baixo consumo; dispositivos economizadores; sistema de aquecimento solar, à 
gás; elevadores eficientes; fontes alternativas de energia; e outros. Categoria 4, Conservação de recursos materiais: qualidade de materiais e componentes; formas e escoras reutilizáveis; gestão de resíduos de construção e demolição; facilidade de manutenção da fachada; madeira plantada ou certificada; e outros. Categoria 5, Gestão da água: medição individualizada; dispositivos economizadores (sistema de descarga; arejadores; registro regulador de vazão); aproveitamento, retenção e infiltração de águas pluviais; áreas permeáveis. Categoria 6, Práticas sociais: educação para a gestão de resíduos da construção e demolição (RCD), educação ambiental dos empregados; desenvolvimento pessoal dos empregados; capacitação profissional dos empregados; inclusão de trabalhadores locais; orientação aos moradores; educação ambiental dos moradores; ações para geração de emprego e renda; e outros. (JOHN; PRADO, 2010, p. 22-24, grifo nosso)

A Câmara Brasileira da Indústria da Construção (CBIC) representa politicamente o setor em âmbito nacional e internacional, reunindo 81 sindicatos e associações patronais do setor da construção, das 27 unidades da Federação. Em conjunto com organizações parceiras, foi elaborado, em 2009, o Programa Construção Sustentável, o qual elenca os temas, respectivos objetivos e ações a serem desenvolvidas.

Quanto aos temas e objetivos específicos, são assim apontados: Água: Utilização racional da água; Desenvolvimento humano: Valorização do ser humano; Energia: Maximização da eficiência energética; Materiais e Sistemas: Utilização de materiais e sistemas Sustentáveis; Meio Ambiente, Infraestrutura e Desenvolvimento Urbano: Viabilização do Desenvolvimento Sustentável; Mudanças Climáticas: Adaptação do Ambiente Construído e Redução de gases de efeito estufa na cadeia produtiva; Resíduos: Diminuição do consumo de recursos naturais. (CBIC, 2009, p. 6-9, grifo nosso)

Com base nos documentos analisados, o setor da indústria da construção considerase sustentável quando a concepção e o conjunto das atividades relacionadas em seu ciclo de vida (extração e beneficiamento de matérias primas, planejamento, projeto, execução, comercialização, uso e operação, manutenção, desmonte e a desconstrução, e gestão dos resíduos resultantes) minimizem os impactos ambientais, e, maximizem benefícios sociais e sua viabilidade econômica. Contudo, vale ressaltar que tanto as certificações internacionais e os documentos nacionais analisados concentram-se no aspecto ambiental.

Isso nos leva a questionar a concepção de sustentabilidade do setor, pois, é sabido que a indústria da construção encontra-se entre aqueles setores que apresentam maiores riscos 
e condições precárias de trabalho, tanto que foi elaborada uma Convenção Internacional do Trabalho sobre Segurança e Saúde na Construção em 1988 e ratificada pelo Brasil em 2006 (Convenção 167, da OIT).

Estudo da OIT destaca que a "ecologização" do setor supõe mudanças no processo de produção e nas condições de trabalho, inclusive no setor da construção. Isso não implica em condições de trabalho mais seguras nas construções sustentáveis em relação às tradicionais. Pelo contrário, apresentam os riscos similares aos da construção tradicional, além do surgimento de novas situações "(como a instalação de equipamento de energia renovável em altura ou a alimentação de redes elétricas inteligentes), combinado com a utilização de novo material de construção (como ladrilhos, materiais de isolamento e pinturas que contenham nanomateriais) também podem ser fontes de riscos e perigos”. (OIT, 2012, p.12)

Frente a esse cenário, é importante enfatizar que não se pode conceber sustentabilidade e, por consequência, trabalho decente. Além dos impactos ambientais, os aspectos ligados ao trabalho também devem ser ressaltados quando se discute sustentabilidade.

Norma Sueli Padilha (2002, p. 42) ressalta que "não é possível vislumbrar a realidade do trabalho sem a concomitante visualização da atividade econômica", e, "não há atividade econômica sem influência ou afetação no meio ambiente que, por sua vez, deve ser preservado buscando-se o necessário equilíbrio na tensão desses interesses" com vistas à continuidade da própria atividade econômica.

Nessa linha de raciocínio, conclui a autora que: "todo esse processo de interrelacionamento da atividade humana na busca do seu desenvolvimento através do trabalho, interagindo com seu meio ambiente, deve ser efetuado de modo que assegure a vida digna de todos".

\subsubsection{Propostas de práticas sociais para a sustentabilidade no setor:}

Com o propósito de verificar como os atores sociais enfrentam tais questões nas ações de sustentabilidade do setor, foram observados os critérios estabelecidos para tal fim no manual do Selo Casa Azul Caixa (categoria 6. "Práticas sociais") (JOHN; PRADO, 2010, p. 176-181) e as ações definidas pelo Programa Construção Sustentável da CBIC (item “Desenvolvimento Humano") (CBIC, 2009, P. 15).

Em relação ao manual do Selo Casa Azul Caixa, o proponente de projeto deve cumprir os seguintes critérios quanto às práticas sociais: 
Educação para a Gestão de Resíduos de Construção e Demolição (RDC). Objetivo: "realizar com os empregados envolvidos na construção do empreendimento atividades educativas e de mobilização para a execução das diretrizes do Plano de Gestão de RCD”. Benefícios: dotar os trabalhadores de "competências relacionadas aos produtos e processos envolvidos na construção, às ferramentas e aos equipamentos utilizados", a fim de proporcionar um melhor gerenciamento dos resíduos gerados nos canteiros de obra e minimizar, por consequência, os impactos ambientais negativos.

Educação Ambiental dos Empregados. Objetivo: "prestar informações e orientar os trabalhadores sobre a utilização dos itens de sustentabilidade do empreendimento, notadamente sobre os aspectos ambientais". Benefícios: conhecimento do público interno quanto às tecnologias ambientais adotadas como "as razões e resultados positivos que trazem ao meio ambiente e à sociedade".

Desenvolvimento Pessoal dos Empregados. Objetivo: Prover educação aos trabalhadores, visando à melhoria das suas condições de vida e inserção social. Indicador: plano de desenvolvimento pessoal para os empregados que contemple iniciativas relacionadas a, no mínimo, uma das seguintes alternativas de ação:

\footnotetext{
$\square$ - educação complementar, via a educação para alfabetização, a inclusão digital, o aprendizado de idiomas estrangeiros, Educação de Jovens e Adultos (EJA), entre outras e perdurar no mínimo pelo período de execução do empreendimento, abrangendo pelo menos $20 \%$ dos trabalhadores;

$\square$ \educação para cidadania, via programas de segurança, saúde e higiene, economia doméstica, educação financeira etc. com carga horária mínima de 8 horas e abranger pelo menos 50\% dos empregados. (JOHN; PRADO, 2010, p. 181)
}

Capacitação profissional dos empregados. Objetivo: melhoria no desempenho de suas funções e condições socioeconômicas. Benefícios: a "combinação de ações voltadas à educação formal e à cidadania, com ações direcionadas à formação geral para o trabalho e à formação profissional, permite a capacitação integral dos trabalhadores, proporcionando-lhes condições de desenvolvimento social e econômico".

Inclusão de trabalhadores locais. Objetivo: "promover a ampliação da capacidade econômica dos moradores da área de intervenção e entorno ou de futuros moradores do empreendimento por meio da contratação dessa população". Benefícios: melhoria das condições de vida dos moradores da área de implantação do empreendimento, com reflexos nas condições do entorno "(aumento da segurança, melhoria do comércio local, melhoria nas condições de manutenção das moradias, etc.)". (JOHN; PRADO, 2010, p. 176-181) 
O Programa Construção Sustentável da CBIC, por sua vez, no item Desenvolvimento Humano, prevê as seguintes ações:

- Mapear e disseminar as boas práticas na adoção de critérios de verificabilidade legal, de responsabilidade socioambiental, de conformidade e de qualidade na cadeia produtiva da construção. Essa ação tem como um dos seus principais objetivos estimular a autorregulação das empresas para verificação permanente do atendimento às leis e adoção de critérios para qualificação dos profissionais, produtos e serviços.

- Mapeamento socioeconômico para identificar a dimensão da demanda por programas de capacitação, educação e conscientização em segurança, meio ambiente, saúde, inovação e sustentabilidade. Estabelecer, com essa finalidade, parcerias entre os sindicatos e associações patronais ligados à CBIC, e também o Senai e o Sesi, para implementação de um programa nacional de capacitação continuada, com ênfase no atendimento às particularidades regionais de educação e qualificação profissional.

- Capacitação de profissionais para aplicação da Lei 11.888/2008, que assegura às famílias de baixa renda assistência técnica pública e gratuita para o projeto e a construção de habitação de interesse social.

- Promover a revisão nacional da grade curricular de universidades, cursos técnicos profissionalizantes e de capacitação de professores dos cursos de formação de profissionais da construção. Essa revisão deve inserir temas específicos e transversais à formalidade, qualidade, conformidade, inovação e sustentabilidade. Além disso, é necessário erradicar o analfabetismo entre os trabalhadores da construção. (CBIC, 2009, p. 15)

Em ambos os documentos, a educação para o desenvolvimento humano e a capacitação profissional foram apontadas, de forma marcante, como mecanismo de benefícios sociais, em especial, quanto às condições de trabalho para o desenvolvimento sustentável do setor.

Nessa linha de raciocínio, constata-se que a capacitação e qualificação profissionais são consideradas como importante aspecto a ser enfrentado com vistas à melhoria da segurança no trabalho; ao aprimoramento no exercício das funções; ao desenvolvimento pessoal; bem como, à conscientização quanto aos impactos ambientais da atividade; por consequência, fundamental para a consecução do trabalho decente na indústria da construção.

No entanto, não serão suficientes sem que haja uma abordagem rigorosa na redução e eliminação dos riscos tradicionais em relação à segurança e à saúde dos trabalhadores, bem como, da identificação dos possíveis riscos novos associados aos novos processos de produção e tecnologias, com adaptação das normas de proteção e programas de controle. Caso contrário, não se poderá conceber a ideia de sustentabilidade na indústria da construção, uma vez que está ausente elemento fundamental: o trabalho decente. 


\section{CONSIDERAÇÕES FINAIS}

A proteção do meio ambiente estabelece uma necessária transição para uma economia sustentável, a qual provoca repercussões nas estruturas de produção e consumo, e, por consequência, nas empresas e no mundo do trabalho. Os novos processos de produção e utilização de novas tecnologias, além de proporcionarem mudanças nos postos de trabalho, resultarão também em novos riscos para os trabalhadores.

Diante desse cenário, a segurança e a saúde do trabalhador são consideradas fatores importantes no debate sobre a economia verde, bem como, para a consecução do trabalho decente, pois são direitos fundamentais do trabalhador. Assim, é necessário criar uma consciência sobre os efeitos dos riscos novos e emergentes associados às tecnologias verdes que alteram os modos de produção, garantindo, desde o princípio, que o trabalho decorrente dessa mudança seja seguro, e ao mesmo tempo, reduzam ao mínimo os efeitos negativos no meio ambiente.

O "esverdeamento" da indústria da construção não implica em condições de trabalho mais seguras. Pelo contrário, apresentam os riscos similares aos da construção tradicional, além do surgimento de novas situações e a utilização de novos materiais de construção que também podem ser fontes de riscos e perigos.

Portanto, a concepção de sustentabilidade em qualquer atividade econômica deve contemplar abordagem rigorosa na redução e eliminação dos riscos tradicionais em relação à segurança e à saúde dos trabalhadores, bem como, da identificação dos possíveis riscos novos associados aos novos processos de produção e tecnologias, com adaptação das normas de proteção e programas de controle. Caso contrário, não se poderá conceber a ideia de sustentabilidade na indústria da construção, uma vez ausente elemento fundamental: o trabalho decente.

\section{REFERÊNCIAS}

BRASIL, Ministério do Meio Ambiente. Cidades sustentáveis. [s.d.]. Disponível em: <http://www.mma.gov.br/cidades-sustentaveis/urbanismosustentavel/constru\%C3\%A7\%C3\%A3o-sustent\%C3\%A1vel>. Acesso em: 13 set. 2015.

BRASIL, Ministério da Previdência Social. Secretaria de Políticas de Previdência Social. Informe de Previdência Social. v. 26, n. 07, jul. 2014. Disponível em: 
$<$ http://www.previdencia.gov.br/wp-

content/uploads/2014/10/Ret_Offset_Informe_julho_2014.pdf >. Acesso em: 07 set. 2015.

CAMARA BRASILEIRA DA INDÚSTRIA DA CONSTRUÇÃO. Desenvolvimento com sustentabilidade. Construção Sustentável. 2009. Disponível em:

<http://www.cbic.org.br/sites/default/files/Programa-Construcao-Sustentavel.pdf >. Acesso em: 24 fev. 2016.

CONFEDERAÇÃO NACIONAL DA INDÚSTRIA; CÂMARA BRASILEIRA DA INDÚSTRIA DA CONSTRUÇÃO. Construção Verde: Desenvolvimento com

Sustentabilidade. Brasília: CNI, 2012. Disponível em:

<http://arquivos.portaldaindustria.com.br/app/conteudo_18/2013/09/23/4970/2013100217585

0295139e.pdf>. Acesso em: 23 fev. 2016.

CONSELHO BRASILEIRO DE CONSTRUÇÃO SUSTENTÁVEL. Aspectos da Construção Sustentável no Brasil e Promoção de Políticas Públicas. 2014. Disponível em:

<http://www.cbcs.org.br/website/aspectos-construcao-

sustentavel/show.asp?ppgCode=31E2524C-905E-4FC0-B784-118693813AC4>. Acesso em:

05 out. 2015.

COSTELLA, Marcelo Fabiano; JUNGES, Franciele Cristina; PILZ, Silvio Edmundo. Avaliação do cumprimento da NR-18 em função do porte de obra residencial e proposta de lista de verificação da NR-18. Ambiente Construído, Porto Alegre, v. 14, n. 3, p. 87-102, jul./set. 2014. p.99-100. Disponível em:

<http://www.seer.ufrgs.br/index.php/ambienteconstruido/article/view/46077/31614>. Acesso em: 24 mar. 2016.

FLORIM, Leila Chagas; QUELHAS, Osvaldo Luiz Gonçalves. Contribuição para a construção sustentável: características de um projeto habitacional eco-eficiente. Engevista, v. 6, n. 3, p. 121-132, dez., 2004 Disponível em:

<http://www.uff.br/engevista/3_6Engevista11.pdf>. Acesso em: 20 set.2015.

GONÇALVES, Edwar Abreu. Manual de segurança e saúde no trabalho. 4. ed. São Paulo: LTr, 2008.

JOHN, Vanderley Moacyr; PRADO, Racine Tadeu Araújo (Coord.). Selo Casa Caixa. Boas práticas para habitação mais sustentável. São Paulo: Páginas \& Letras - Editora e Gráfica, 2010. Disponível em:< http:// www.caixa.gov.br/Downloads/selo_azul/Selo_Casa_Azul.pdf>. Acesso em: 13 set.2015.

ORGANIZAÇÃO DAS NAÇÕES UNIDAS. Agenda 21, 1992a. Cap.7. Disponível em <http://www.onu.org.br/rio20/img/2012/01/agenda21.pdf>. Acesso em: 29 set. 2015.

Declaración de Johannesburgo sobre el Desarrollo Sostenible. In:

Cumbre Mundial sobre el Desarrollo Sostenible, Johannesburgo, 2002. Disponível em: < http://www.un.org/spanish/esa/sustdev/WSSDsp_PD.htm>. Acesso em: 10 mar. 2015.

. Declaración de Rio sobre el Medio Ambiente y el Desarrollo. In: Cumbre Mundial sobre el Medio Ambiente e el Desarollo, Rio de Janeiro, 1992b. Disponível 
em:〈http://www.un.org/spanish/esa/sustdev/agenda21/riodeclaration.htm>. Acesso em: 10 mar. 2015.

Resolución aprobada por la Asamblea General el 27 de julio de 2012.

Disponível em:

<http://www.pnuma.org/sociedad_civil/documents/reunion2012/CIVIL\%20SOCIETY\%20PA RTICIPATION/20120727\%20Rio+20\%20Documento\%20E1\%20futuro\%20que\%20queremo s.pdf>. Acesso em 13 fev. 2015.

. Sustainable Development. Transforming our world: the 2030 Agenda for Sustainable Development, 2015. Disponível em:

<https://sustainabledevelopment.un.org/post2015/transformingourworld>. Acesso em: 17 ago 2015.

ORGANIZAÇÃO INTERNACIONAL DO TRABALHO. Promover la seguridad y la salud en una economía verde, 2012. Disponível em: <http://www.ilo.org/wcmsp5/groups/public/--ed_protect/---protrav/---safework/documents/publication/wcms_176314.pdf>. Acesso em: 5 ago. 2016.

PADILHA, Norma Sueli. Do meio ambiente do trabalho equilibrado. São Paulo: LTr, 2002.

PROGRAMA DE LAS NACIONES UNIDAS PARA EL MEDIO AMBIENTE. Oficina Regional para América Latina y el Caribe. Economía Verde en El contexto del desarrollo sostenible y erradicación de la pobreza: Una perspectiva desde América Latina y el Caribe. In: XVIII Reunión del Foro de Ministros de Medio Ambiente de América Latina y el Caribe Quito, Ecuador 31 de enero al 3 de febrero de 2012. Disponível em: $<$ http://www.pnuma.org/forodeministros/18ecuador/Reunion\%20Expertos/Informe\%20Economia\%20Verde/ESPANOL\%20Economia\% 20Verde\%2016\%20DEC\%202011.pdf.> Acesso em: 21 jul. 2015

ROCHA, Júlio Cesar de Sá da. Direito ambiental do trabalho: mudança de paradigma na tutela jurídica à saúde do trabalhador. São Paulo: LTr, 2002.

SALGADO, Mônica Santos; CHATELET, Alain; FERNANDEZ, Pierre. Produção de edificações sustentáveis: desafios e alternativas. Ambiente Construído, Porto Alegre, v. 12, n. 4, p. 81-99, out./dez. 2012. Disponível em:

<http://scholar.google.com.br/scholar_url?url=http://www.seer.ufrgs.br/ambienteconstruido/ar ticle/download/22603/23734\&hl=pt-BR\&sa=X\&scisig=AAGBfm1AtbhTzHX2t-

kdcoTEB2ZnVJ3mwA\&nossl=1\&oi=scholarr\&ved=0ahUKEwjj0OKfzoTMAhUBWT4KHbI OC_UQgAMIGygAMAA> . Acesso em: 29 fev. 2016.

SUSSEKIND, Arnaldo et. al. Instituições de direito do trabalho. 18. ed. São Paulo: LTr, 1999.

UNITED NATIONS ENVIRONMENT PROGRAMME. Sustainable buildings and construction Programme. [20--]. Disponível em:

<http://www.unep.org/10yfp/Programmes/ProgrammeConsultationandCurrentStatus/Sustaina blebuildingsandconstruction/tabid/106268/Default.aspx>. Acesso em 07 set 2015. 
UNITED NATIONS ENVIRONMENT PROGRAMME; INTERNATIONAL ENVIRONMENTAL TECHNOLOGY CENTRE (UNEP-IETC); INTERNATIONAL COUNCIL FOR RESEARCH AND INNOVATION IN BUILDING AND

CONSTRUCTION (CIB). Agenda 21 for Sustainable Construction in Developing Countries, 2002. Disponível em: <http://www.unep.or.jp/ietc/Focus/Agenda\%2021\%20BOOK.pdf〉. Acesso em: 23 out. 2015. 